See discussions, stats, and author profiles for this publication at: https://www.researchgate.net/publication/353587799

\title{
Seasonal not annual precipitation drives 8-year variability of interannual net CO2 exchange in a salt marsh
}

Article in Agricultural and Forest Meteorology · October 2021

Dol: 10.1016/j.agrformet.2021.108557

CITATIONS

12 authors, including:

A) Xiaojing Chu

4 Yantai institute of coastal zone research Chinese academy of science 19 PUBLICATIONS 261 CITATIONS

SEE PROFILE

Qinghui Xing

Chinese Academy of Sciences

14 PUBLICATIONS 310 CITATIONS

SEE PROFILE

Some of the authors of this publication are also working on these related projects:

US-China Carbon Consortium (USCCC) View project

Project Litter decomposition in terrestrial ecosystems View project
READS

59

Guangxuan Han

Chinese Academy of Sciences

101 PUBLICATIONS 1,365 CITATIONS

SEE PROFILE

A Sun Baoyu

East China Normal University

10 PUBLICATIONS 75 CITATIONS

SEE PROFILE 


\title{
Seasonal not annual precipitation drives 8-year variability of interannual net $\mathrm{CO}_{2}$ exchange in a salt marsh
}

\author{
Xiaojing Chu ${ }^{\text {a,b,c }}$, Guangxuan Han ${ }^{\text {a,b,c, }}$, Siyu Wei ${ }^{\text {a,b,c }}$, Qinghui Xing ${ }^{\text {d }}$, Wenjun He ${ }^{\text {a,b,c }}$, \\ Baoyu Sun ${ }^{\mathrm{a}, \mathrm{e}}$, Xinge $\mathrm{Li}^{\mathrm{a}}{ }^{\mathrm{b}, \mathrm{c}}$, Dafeng Hui ${ }^{\mathrm{f}}$, Haitao $\mathrm{Wu}^{\mathrm{g}}$, Xiaojie Wang ${ }^{\mathrm{a}, \mathrm{b}, \mathrm{c}}$, Peiguang Li ${ }^{\mathrm{a}, \mathrm{b}, \mathrm{c}}$, \\ Weimin Song ${ }^{\mathrm{a}, \mathrm{b}, \mathrm{c}}$ \\ ${ }^{a}$ CAS Key Laboratory of Coastal Environmental Processes and Ecological Remediation, Yantai Institute of Coastal Zone Research (YIC), Chinese Academy of Sciences \\ (CAS), Shandong Key Laboratory of Coastal Environmental Processes, YICCAS, Yantai Shandong 264003, P. R. China \\ ${ }^{\mathrm{b}}$ Center for Ocean Mega-Science, Chinese Academy of Sciences, 7 Nanhai Road, Qingdao, 266071, P. R. China \\ ${ }^{\mathrm{c}}$ Yellow River Delta Field Observation and Research Station of Coastal Wetland Ecosystem, Chinese Academy of Sciences, Dongying 257000, Shandong, China \\ ${ }^{\mathrm{d}}$ National Marine Environmental Monitoring Center, Ministry of Ecology and Environment of the People's Republic of China, Dalian, 116023, P. R. China \\ e School of Ecological and Environmental Sciences, East China Normal University, Shanghai, 200241, China \\ ${ }^{\mathrm{f}}$ Department of Biological Sciences, Tennessee State University, Nashville, TN 37209 USA \\ ${ }^{\mathrm{g}}$ Northeast Institute of Geography and Agroecology, Chinese Academy of Sciences, Changchun 130102, China
}

\section{A R T I C L E I N F O}

\section{Keywords:}

sseasonal precipitation distribution

NEE

interannual variability

plant biomass

water-salt transport

salt marsh

\begin{abstract}
A B S T R A C T
Salt marshes are significant contributors to global "blue carbon" resources, and these habitats are sensitive to precipitation events due to periodically dry-wet alternation induced by tides. However, whether annual marshatmospheric $\mathrm{CO}_{2}$ flux responds more to annual or seasonal precipitation remains unclear. Here, eight years (2012-2019) of eddy covariance data were evaluated to determine typical $\mathrm{CO}_{2}$ budgets, and we assessed the effect of annual and seasonal precipitation on interannual net ecosystem $\mathrm{CO}_{2}$ exchange (NEE) in a salt marsh of the Yellow River Delta, China. The salt marsh was a sink for atmospheric $\mathrm{CO}_{2}$ in each of the eight study years, with an 8-year average NEE of $-51.7 \pm 9.7 \mathrm{~g} \mathrm{C} \mathrm{m}^{-2} \mathrm{a}^{-1}$ varying from -8 to $-85 \mathrm{~g} \mathrm{C} \mathrm{m}^{-2} \mathrm{a}^{-1}$. Annual NEE was mainly regulated by precipitation levels during the early growth stage of plants, which modulated maximal plant biomass accumulation via water-salt transport. Besides, a spring precipitation distribution experiment showed that wetter early growth stage of plants enhanced carbon assimilation capacity in the salt marsh by decreasing soil salinity and promoting plant biomass accumulation. These findings suggest that soil water-salt conditions induced by precipitation during the onset of the growing season are crucial for interannual variations of NEE in salt marshes.
\end{abstract}

\section{Introduction}

Salt marshes are considered as significant sinks for global carbon (C) and contributors to global "blue carbon" resources (Zhong et al., 2016). Due to low elevation and proximity to the ocean, shallow and saline groundwater occurs in many salt marshes, with the extent varying under different geologic settings (Hoover et al., 2017). Different from freshwater wetlands, salt marshes are subjected to periodic tidal flooding, which enhances their ability to trap and bury significant amounts of allochthonus carbon (Poffenbarger et al., 2011, Wu et al., 2013, Han et al., 2018). Further, anaerobic conditions driven by tidal periodic flooding hinders $\mathrm{CO}_{2}$ production, leading to the low emissions of $\mathrm{CO}_{2}$ and a high ability to sequester C in salt marshes (Han et al., 2015). Additionally, the presence of abundant sulfate carried by tidal flooding hinders $\mathrm{CH}_{4}$ production, leading to the low emissions of $\mathrm{CH}_{4}$ from salt marshes (Drake et al., 2015). Finally, alternating dry-wet conditions induced by tides can lead to changes in the hydrological condition and soil properties of salt marshes (Chmura et al., 2011), leading to constantly changing salt accumulation and leaching, which has the potential to significantly alter the $\mathrm{C}$ mineralization rates, microbial activity and nutrient dynamics (Wei et al., 2020a, Han et al., 2018).

Salt marshes are sensitive to precipitation events that modify the

\footnotetext{
* Corresponding author: Tel.: +86 535 2109218, Key Laboratory of Coastal Zone Environmental Processes and Ecological Remediation, Yantai Institute of Coastal Zone Research, Chinese Academy of Sciences, 264003 Yantai, Shandong, China

E-mail address: gxhan@yic.ac.cn (G. Han).
} 
periodically dry-wet cycles induced by tides (Han et al., 2015). Variation in marsh biomass production is most often explained by variation in drivers that affect soil salinity levels, and high soil salinity levels reduce biomass production (Morris et al., 2002, Wieski and Pennings, 2014, Hanson et al., 2016). On the one hand, when precipitation is low, coupled with increased air temperatures and evaporation rates, water-soluble salts from the sub-surface groundwater are transported upward through the root zone of plants to the soil surface from capillary rise (Yao and Yang 2010). Salinity stress tends to inhibit photosynthesis and productivity of marsh plants by influencing the leaf chlorophyll content, protein synthesis, and lipid metabolism of marsh plants (Abdul-Aziz et al., 2018, Wei et al., 2020b). Therefore, in many salt marshes, periodic inputs of freshwater from precipitation controls structure and function of their plant communities (Heinsch et al., 2004). On the other hand, heavy rains usually caused episodic flooding over the shallow underground water (Han et al., 2015). The stress induced by rainfall-driven water-logging may not only suppress net photosynthetic rates, but the soil hypoxia or anoxia may also decrease overall plant metabolic activity (Schedlbauer et al., 2010). Therefore, water-salt transport induced by precipitation likely has big impacts on many ecosystem processes, especially for ecosystem $\mathrm{CO}_{2}$ fluxes (Hu et al., 2017, Chu et al., 2018). For example, during drought, high salinities can shift salt marshes' plant functional group dominance, change the aboveground biomass, and finally suppress annual NEE (Yando et al., 2016, Chu et al., 2018). In contrast, with heavy rains, the episodic flooding could reduce the daytime net $\mathrm{CO}_{2}$ uptake and maximum rates of photosynthesis due to the partial or complete submersion of plants and soil (Han et al., 2015). Thus, in addition to tides, precipitation variation is likely also a vital driver, which will control the seasonal or annual variability in carbon exchange for a salt marsh.

On local to regional scales, both increases and decreases in total precipitation occur, and these changes can be accompanied by changes in the frequency, duration, or seasonality of particularly heavy precipitation events (Emery 2019). Previous studies have found that total precipitation amount affects carbon budgets (Liu et al., 2016), but others have shown that the seasonality of precipitation distribution may play an even more important role than annual precipitation totals in regulating ecosystem C cycling (Hovenden et al., 2014, Zeppel et al., 2014, Ru et al., 2017). Thus, the question arises, which aspect of precipitation is most important for the $\mathrm{C}$ exchange in tidal salt marshes: the annual total or the seasonality? In this study, using the eddy covariance (EC) technique, we conducted 8 years of continuous $\mathrm{CO}_{2}$ flux measurements from January 2012 to December 2019 in a high salt marsh of the Yellow River Delta. Our objectives were: (1) to quantify seasonal and inter-annual variability of $\mathrm{NEE}$ and annual $\mathrm{CO}_{2}$ sink-source strength of the salt marsh, and (2) to examine which factor plays the most important role in regulating annual NEE, annual or seasonal precipitaiton?

\section{Material and Methods}

\subsection{Study region}

This study was conducted at a high tidal flat of a salt marsh in the Yellow River Delta, northeast China $\left(37^{\circ} 47^{\prime} 20^{\prime \prime} \mathrm{N}, 119^{\circ} 10^{\prime} 23^{\prime \prime} \mathrm{E}\right)$ (Fig. 1b). The region is characterized as a warm-temperate and continental monsoon climate with dry springs and rainy summers. It was about 2.8 kilometers away from the coast (Fig. 1b), tidal inundation at the site occurred only during spring tides due to the high tidal flat. The hydrological characteristics of the salt marsh are affected by the interactions between precipitation and groundwater in the vertical direction, and seawater and freshwater fluxes in the horizontal direction. Especially, water-soluble salts in deep soil can be transferred to the soil surface through capillary rise and evaporation due to low underground water table. Plant growth depends greatly on fresh water supply from precipitation. The mean annual temperature is $12.9^{\circ} \mathrm{C}$, and the average annual precipitation is $560 \mathrm{~mm}$, with nearly $70 \%$ falling between June and September (Han et al., 2015). The drying and wetting cycles induced by precipitation or tide can lead to an alternation of salt accumulation and leaching. Due to harsh physical conditions, the flora is relatively simple and the only common species is Suaeda salsa (L.) Pall (Fig. 1c), with a maximum height of $20-40 \mathrm{~cm}$ and coverage of $30-60 \%$. S. salsa is an annual herb, with the germination stage at the end of March, flowering in early August, and fade in late November. Considering the footprints, the flux tower was installed in $S$. salsa within a radius of 200 meters and mean coverage of $45 \%$ (Fig. 1d). The soil type is coastal saline colluvial soil, and the soil texture is mainly sandy clay loam.
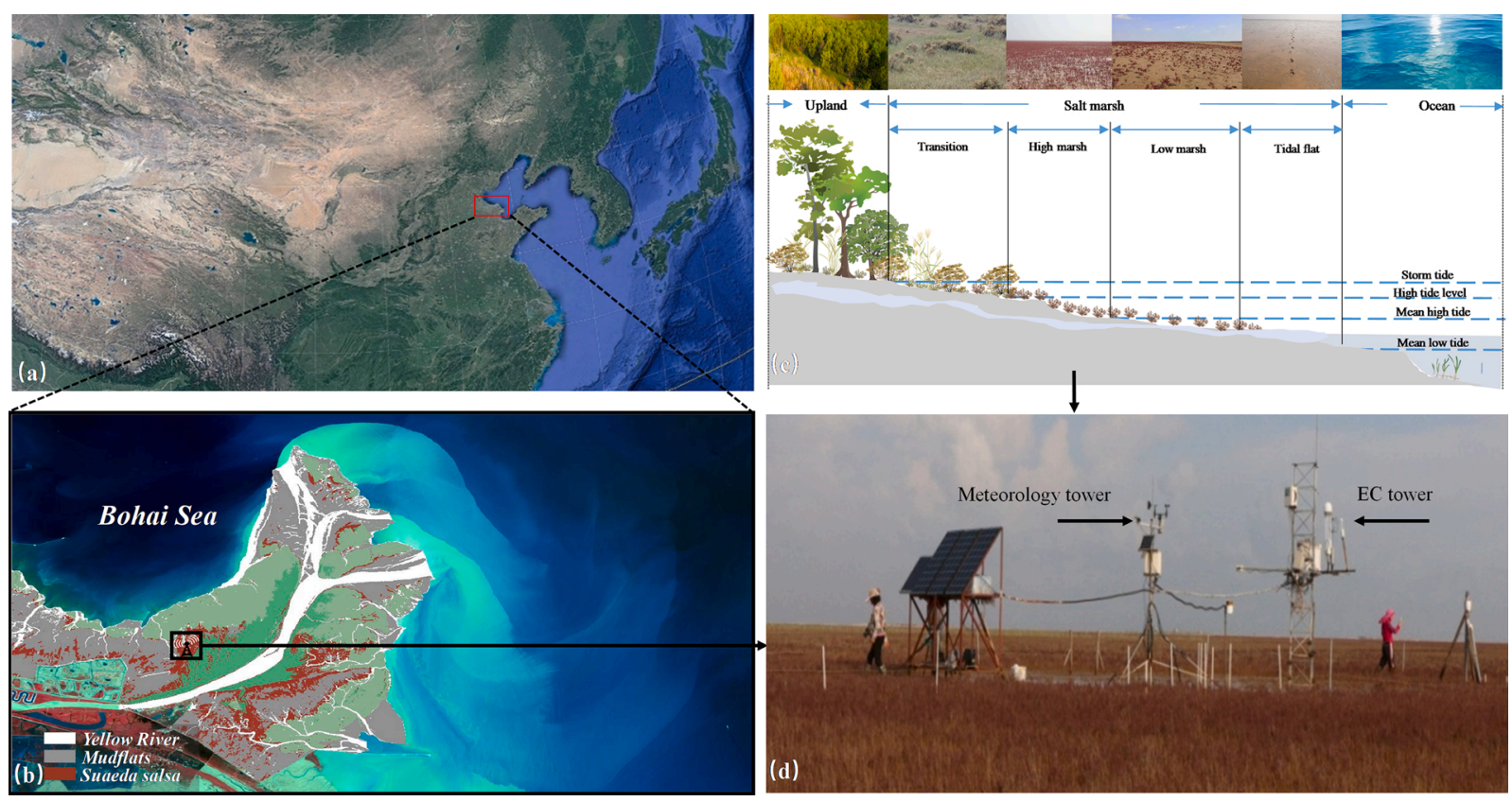

Figure 1. Study region of the Yellow River Delta (a), location of flux tower (b), vegetation distribution pattern of coastal zone (c), and EC tower (d). 


\subsection{Division of plant growth stages}

In this study, plant growth stages of the natural growth cycle were divided based on phenology and growth characteristics of $S$. salsa. Early growth stage (March to April) was defined as the time between germination and rapid growth, biomass started to grow but increased slowly during this period. Middle growth stage (May to August) was defined as the stage from rapid growth to the peak biomass, biomass increased rapidly during this stage. Terminal growth stage (September to November) was defined as the period from the peak biomass to withering, aboveground living biomass decreased gradually and eventually senesced during this period. During the winter stage (December to February), defined as the period of plant withering period, biomass was zero during this stage.

\subsection{Eddy covariance, meteorological and biomass measurements}

Net ecosystem $\mathrm{CO}_{2}$ fluxes (NEE) and water vapor $\left(\mathrm{H}_{2} \mathrm{O}\right)$ fluxes were continuously measured from the beginning of the year 2012 till the end of the year 2019, using an eddy covariance (EC) system mounted on a tower $2.8 \mathrm{~m}$ above the soil surface (Fig. 1d). The open-path EC system at the tower consisted of an open-path infrared $\mathrm{CO}_{2} / \mathrm{H}_{2} \mathrm{O}$ gas analyzer (LI7500A, LI-COR, Lincoln, NE), a three-axis sonic anemometer (GILL-wind master pro, GILL corporation, London, England), and an Analyzer Interface Unit to record high-frequency data (Li-7550, Li-COR, Lincoln, $\mathrm{NE}$ ). The raw flux data were collected and stored on a 4-GB disk with a 10-Hz recording frequency in the unit.

Meteorological parameters were continuously measured with an array of sensors, including air temperature $\left(\mathrm{T}_{\text {air }}\right)$ thermometer at a height of $2 \mathrm{~m}$, photosynthetically active radiation (PAR) and total solar radiation (TSR) sensors at a height of $2.8 \mathrm{~m}$, precipitation (PPT) sensor at a height of $1.5 \mathrm{~m}$, and soil temperature $\left(\mathrm{T}_{\text {soil }}\right)$ thermometer inserted to a depths of $10 \mathrm{~cm}$, transmitting at a frequency of $10 \mathrm{~Hz}$ continuously. A data logger (CR1000, Campbell Scientific Inc. USA) was used to collect micrometeorological data at a 1-min intervals, and these data were compiled into half-hourly data using the built-in automatic data program, and stored in the memory of the data logger.

Plant biomass of aboveground and belowground for salt marshes was measured by harvesting the vegetation approximately twice a month from May to October. Harvesting was performed in five replicated sampling plots $(0.5 \mathrm{~m} \times 0.5 \mathrm{~m})$ located within a radius of $200 \mathrm{~m}$ around the EC system. Entire live plants were uprooted by digging whole plants with a pick. Plant material was oven dried at $80^{\circ} \mathrm{C}$ to a constant mass before weighing.

Flux data processing followed standard methods and included despiking, coordinate rotation, time lag corrections, and air density corrections (Webb et al., 1980, Polsenaere et al., 2012). More details about flux data processing, quality control, and gap filling can be found in Chu et al., (2018).

NEE was partitioned into two components of gross primary productivity (GPP) and ecosystem respiration ( $R_{\text {eco }}$ ) (Schedlbauer et al., 2010), the relationship between them is as follows:

$N E E=R_{\text {eco }}-G P P$

$\mathrm{R}_{\text {nighttime }}$ was nighttime NEE When $\mathrm{R}_{\mathrm{n}}$ was $<10 \mathrm{~W} \mathrm{~m}{ }^{-2}$, $\mathrm{R}_{\text {daytime }}$ is calculated by the predictive relationships developed for nighttime periods:

$R=a \exp (b T)$

When $\mathrm{R}$ is $\mathrm{R}_{\text {nighttime, }} \mathrm{T}$ is nighttime air temperature, and $\mathrm{a}$ and $\mathrm{b}$ are two empirical coefficients; When $\mathrm{R}$ is $\mathrm{R}_{\text {daytime, }} \mathrm{T}$ is daytime air temperature.

Daily ecosystem respiration $\left(R_{\text {eco }}\right)$ is the sum of daytime ecosystem respiration $\left(\mathrm{R}_{\text {daytime}}\right)$ and the nighttime ecosystem respiration ( $\left.\mathrm{R}_{\text {nighttime }}\right)$ :

$$
R_{\text {eco }}=R_{\text {daytime }}+R_{\text {nightime }}
$$

Energy balance closure is calculated by energy balance ratio (EBR), which is the ratio of the sum of sensible and latent heat fluxes (H + LE) versus net radiation $\left(R_{n}\right)$ minus soil heat flux $(G)$ (Suyker and Verma, 2012). The annual mean EBR was 0.75 from 2012 to 2019, which was within the range previously reported for salt marshes (He et al., 2021).

\subsection{Spring precipitation distribution experiment}

In order to verify the effect of seasonal precipitation on soil watersalinity transport and net ecosystem $\mathrm{CO}_{2}$ exchange, we designed a spring precipitation distribution experiment (from March to May) in March 2020 in the Yellow River Delta. A $17 \times 13 \mathrm{~m}^{2}$ rainout shelter $(2.2$ $\mathrm{m}$ high at the roof and $2.0 \mathrm{~m}$ at the edge) with steel frames covered with clear polyethylene roofs were used to control precipitation inputs. A gradient of simulated rain was set according to the long-term spring precipitation threshold values from 1961 to 2018: CK, precipitation was simulated according to the long-term mean values of spring from 1988 to 2018 ; $+56 \%$, precipitation increased by $56 \%$ compared to $\mathrm{CK} ;-56 \%$, precipitation decreased by $56 \%$ compared to CK. There are twelve $3 \times$ $3 \mathrm{~m}^{2}$ plots and were randomly assigned, with 4 replicates each treatment. Natural precipitation was intercepted by the rainout shelter, collected through a U-shaped plastic tank at the edge of the rain shelter, stored in four white plastic buckets which were buried $4 / 5$ underground. The collected rainwater was applied manually back to the plots assigned to the three treatments. Each plot simulated rainfall four times per month, and interval 7-8 days. As the precipitation was insufficient, and tap water was supplied in one plot of each treatment.

Soil salinity at $10 \mathrm{~cm}$ depth approximately were measured every 30 min using sensors of 5TE (Decagon, USA). Considering data of soil moisture and salinity measured by sensors can interfere with each other, we measured soil salinity and water content by collecting soil samples every two weeks. Net ecosystem $\mathrm{CO}_{2}$ exchange (NEE) was measured by a transparent chamber $(0.6 \mathrm{~m}$ diametral; $0.7 \mathrm{~m}$ height $)$ attached to infrared gas analyser (Li-6400, LI-COR). In November 2019, a circular arcrylic frame ( $0.6 \mathrm{~m}$ diametral; $0.1 \mathrm{~m}$ height) was inserted into the soil at $7 \mathrm{~cm}$ depth in each plot. This static-chamber method has been successfully used to evaluate plot level fluxes of $\mathrm{CO}_{2}$ in previous studies, and details about the measurement methods of NEE can be found in previous studies (Sun et al., 2021). NEE was measured twice a month on clear, sunny days between 9:00 and 11:00 during the spring in 2020 .

\subsection{Wavelet analysis}

Wavelet analysis has been widely applied to the geophysical and ecological time series (Jia et al., 2018). We deployed wavelet coherence (WTC) to quantify the relationship between NEE and one variable. Besides, partial wavelet coherence (PWC) was used to identify the coherence between NEE and one variable after eliminating the confounding effect of other variables. All wavelet analyses were calculated in Matlab 2019a software by codes distributed by Ng and Chan (2012).

\subsection{Data analysis}

Before statistical analysis, the normality and homoscedasticity of all data were tested. In order to provide estimates for the balance of NEE, small gaps $(<2 \mathrm{~h})$ were filled by linear interpolation using the neighboring measurements, and large gaps $(>2 \mathrm{~h}$ ) of daytime and nighttime were filled by Michaelis-Menten model and the exponential regression analysis, respectively (Han et al., 2014). Based on the assumption that $\mathrm{R}_{\text {eco,daytime }}$ was of similar magnitude and responsiveness as $R_{\text {eco,nighttime, }}$ $\mathrm{R}_{\text {eco,daytime }}$ was determined using the predictive relationships developed for nighttime periods. Daily $R_{\text {eco }}$ is the sum of $R_{\text {eco,daytime }}$ and $R_{\text {eco, }}$ nighttime. GPP was calculated as residual between NEE and $R_{\text {eco. }}$ 
The multiple linear regression was used to study the joint influence of main environment factors (PAR, $\mathrm{T}_{\text {air }}$, PPT) and biomass. Pearson correlation analysis was conducted to probe the correlations between annual NEE and main environmental factors and biomass. Multiple regression analysis with forward variable selection was used to explore the annual key factors among PPT, $\mathrm{T}_{\text {air }}$ and PAR during different growth stages that controlled annual maximal biomass. Considering that many of the environmental variables were auto-correlated and co-varied with each other, Pearson correlation analysis was applied to investigate the correlations between the annual daily mean PAR and $\mathrm{T}_{\text {air }}$ during the early growth. In the spring precipitation distribution experiment, soil salinity and NEE were calculated as the mean of four replicates at random locations for each treatment. The repeated measure analysis of variance was used to test the differences in NEE. All statistical analyses were performed using the SPSS 17.0 (SPSS Inc. Chicago, IL, USA). Probabilities less than 0.05 were considered significant for all statistical analyses.

\section{Results}

\subsection{Seasonal and inter-annual meteorological conditions and NEE}

The seasonal trends of the daily averaged photosynthetically active radiation (PAR), air temperature $\left(\mathrm{T}_{\text {air }}\right)$, and soil temperature $\left(\mathrm{T}_{\text {soil }}\right)$ at 10 $\mathrm{cm}$ depth were similar from year to year, and they all had a single peak and reached their maximums in July or August (Fig. 2a and 1b). The mean annual PAR, $\mathrm{T}_{\text {air }}$ and $\mathrm{T}_{\text {soil }}$ were $298 \mu \mathrm{mol} \mathrm{m}^{-2} \mathrm{~s}^{-1}$, and 13.0 and 14. $5^{\circ} \mathrm{C}$, respectively. Annual precipitation over the 8 years was $638 \mathrm{~mm}$ with large inter-annual variation, ranging from $325 \mathrm{~mm}$ (recorded in 2014) to $931 \mathrm{~mm}$ (in 2016) (Table S1, Fig. 2c). The inter-annual variations of seasonal precipitation expressed in terms of standard deviation (SD) and coefficient of variation (CV, \%) are showed in table S2. The biomass started to increase during early growth stage in April to a peak at middle growth stage, and decreased as plants senesced during terminal growth stage. However, their seasonal variation patterns differed markedly among years (Fig. 2d).

NEE exhibited clear seasonal variation, with a net sink of $\mathrm{CO}_{2}$ during the growing seasons and a net source of $\mathrm{CO}_{2}$ for the non-growing seasons at the seasonal scale (Fig. 2e). Daily averaged NEE was also subjected to large inter-annual variability, reaching from $-0.80 \mathrm{~g} \mathrm{C} \mathrm{m}^{-2} \mathrm{~d}^{-1}$ in 2013 to $0.23 \mathrm{~g} \mathrm{C} \mathrm{m}^{-2} \mathrm{~d}^{-1}$ in 2016 (Fig. 2e). In particular, a weak net $\mathrm{CO}_{2}$ sequestration was observed in 2016 (Fig. 1e), which corresponded to lowest biomass (Fig. 2d). In addition to their seasonal variability, daily averaged $R_{\text {eco }}$ and GPP exhibited large inter-annual differences (Fig. $2 f$, $2 \mathrm{~g}$ ). The annual accumulative NEE showed that there were net $\mathrm{CO}_{2}$ uptakes by the ecosystem, ranging from $-8 \mathrm{~g} \mathrm{C} \mathrm{m}^{2} \mathrm{yr}^{-1}$ to $-85 \mathrm{~g} \mathrm{C} \mathrm{m}^{2} \mathrm{yr}^{-1}$ from 2012 to 2019 (Fig. 3a, Table S1). Gross primary productivity (GPP) from 2012 to 2019 were $115,151,124,139,58,109,108$ and $87 \mathrm{~g} \mathrm{C} \mathrm{m}^{2}$ $\mathrm{yr}^{-1}$ (Fig. 3b), and $\mathrm{R}_{\text {eco }}$ were 53, 65, 87, 67, 50, 63, 55 and $48 \mathrm{~g} \mathrm{C} \mathrm{m}^{2}$ $\mathrm{yr}^{-1}$, respectively (Fig. 3c, Table S1). Besides, the daily aggregated NEEGPP displayed consistent linear correlation (2012-2019: $\mathrm{R}^{2}=0.80, \mathrm{P}<$ 0.01 ) during different growth stages across the 8 years (Fig. S1a). The data points of GPP plotted versus $R_{\text {eco }}$ fell above the 1:1 line, indicating that the ecosystem was acting as a net $\mathrm{CO}_{2}$ sink (Fig. S1b).

\subsection{Correlations between NEE and environmental factors at multiple timescales}

The correlations between NEE and environmental factors at multiple timescales were tested using wavelet coherence analysis (WTC) and partial wavelet coherence analysis (PWC). Significant continuous areas were observed at annual scale (periods between 256 and 512 days) between NEE and main environmental factors (Fig. 4). Notably, NEE was also tightly correlated with biomass and PPT at periods more than 512 days (Fig. 4c and 4d).

We further used PWC to disentangle the confounding effects of environmental factors on NEE (Fig. 5). The most interesting part of the PWC analysis was the opposite result between PWC (NEE-PPT, Biomass) and PWC (NEE-Biomass, PPT) (Fig. 5a and 5b). The continuous significant areas in PWC (NEE-Biomass, PPT) revealed a greater effect of biomass than that of PPT on NEE at annual scale (periods $>256$ days). However, the significant areas between NEE and biomass disappeared at the beginning of 2016, which was in line with the sudden reduction of biomass in 2016 (Fig. 2d). Moreover, PWC analysis also revealed that biomass rather than PAR or $\mathrm{T}_{\text {air }}$ dominated the variation of NEE at periods longer than 512 days (Fig. $5 c$ and $5 d$ ).

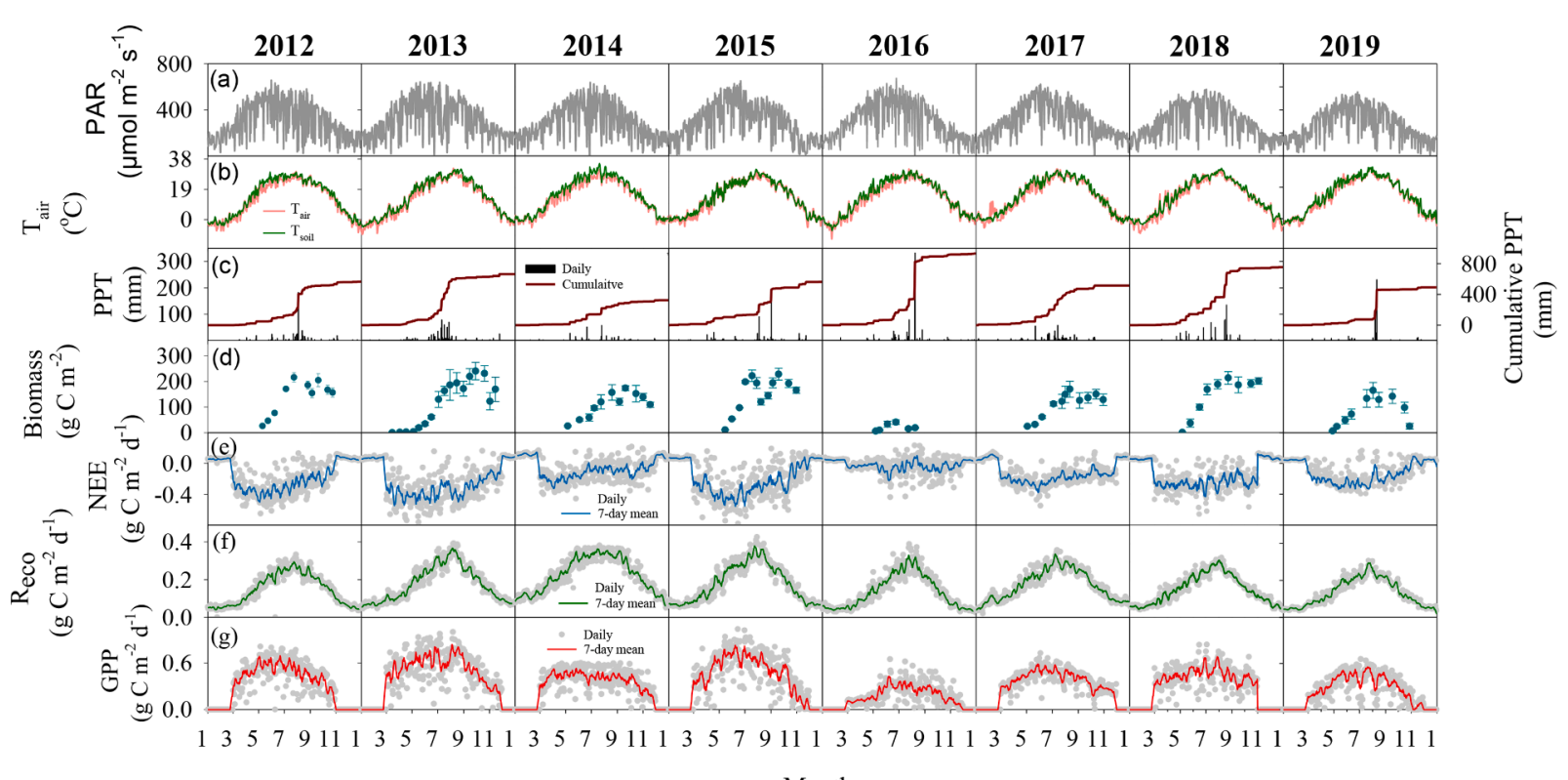

Month

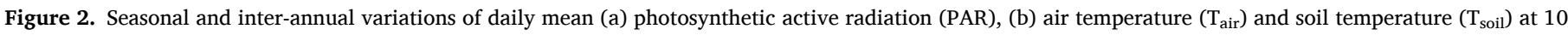

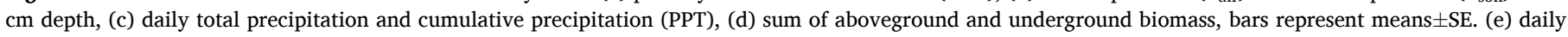

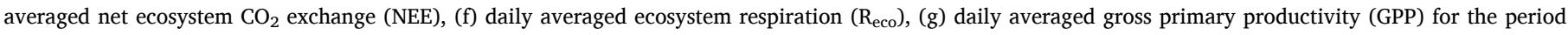
of 2012-2019. 

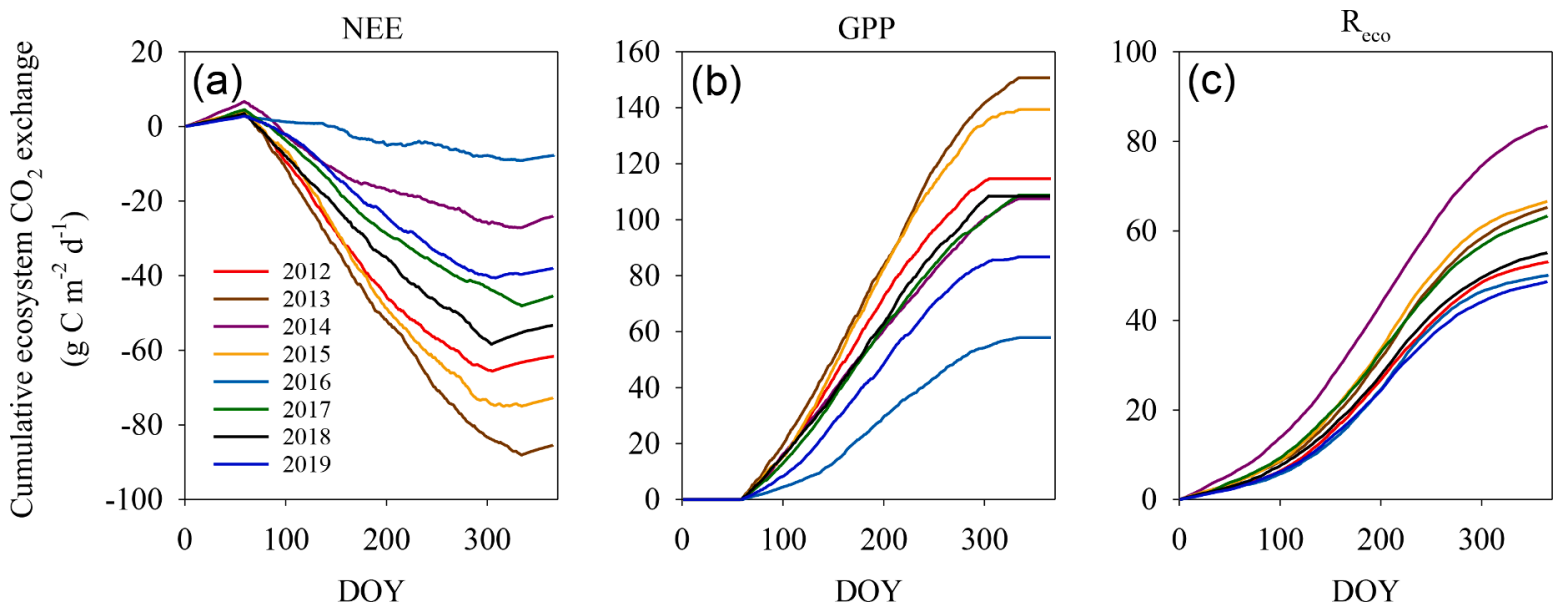

Figure 3. Cumulative (a) net ecosystem $\mathrm{CO}_{2}$ exchange (NEE), (b) gross primary productivity (GPP) and (c) ecosystem respiration ( $\mathrm{R}_{\text {eco }}$ ) from 2012 to 2019.


Figure 4. Wavelet coherence (WTC) between net ecosystem $\mathrm{CO}_{2}$ exchange (NEE) and (a) photosynthetic active radiation (PAR), (b) air temperature ( $\mathrm{T}_{\text {air }}$ ), (c) biomass, (d) precipitation (PPT) from 2012 to 2019. Black contour lines represent the 0.05 significance level, and the thin line indicates the cone-of-influence that delimits the region not influenced by edge effects. The phase difference is shown by arrows. Arrows pointing up indicate environmental factors lagging NEE by $90^{\circ}$ or leading NEE by $270^{\circ}$, while arrows pointing down indicate environmental factors leading NEE by $90^{\circ}$ or lagging NEE by $270^{\circ}$. Arrows pointing right (left) indicate environmental factors and NEE vary in-phase (anti-phase).

\subsection{Effect of annual and seasonal precipitation on annual NEE}

On inter-annual scale, annual NEE was significantly linearly decreased with maximal biomass $\left(\mathrm{R}^{2}=0.87, \mathrm{P}<0.01\right.$, Fig. 6a), but showed no relationship with $\mathrm{T}_{\text {air }}$ (Fig. 6b), annual total precipitation (Fig. 6c), or PAR (Fig. 6d) (P > 0.05). On seasonal scale, annual mean NEE was driven by precipitation during the early growth stage, showing a significant negative linear relationship (Fig. 6e). Specially, note that there was a highly significant correlation between maximal biomass and precipitation during the early growth stage (Fig. S2, $\mathrm{R}^{2}=0.41, \mathrm{P}<$ 0.05 ), indicating seasonal precipitation affected annual NEE by regulating biomass accumulation. Besides, the ratio between maximal biomass and GPP was defined by a strong linear relationship (Fig. S3, slope $=2.08, \mathrm{R}^{2}=0.83$ ).

\subsection{Effect of spring precipitation change on soil salinity and NEE}

Measurements on the spring precipitation distribution platform in 2020 spring showed a marked divergence trend towards decreased salinity with increased spring precipitation distribution (Fig. 7a). The soil salinity under $+56 \%$ treatment was the lowest, about $8 \%$ lower than that under CK. The $-56 \%$ treatment was the highest, about $14 \%$ higher than that under CK. NEE showed a significant increasing pattern with increased precipitation distribution (Fig. 7b). Besides, there was a significant linear positive correlation between NEE and soil salinity (Fig. 7c). 


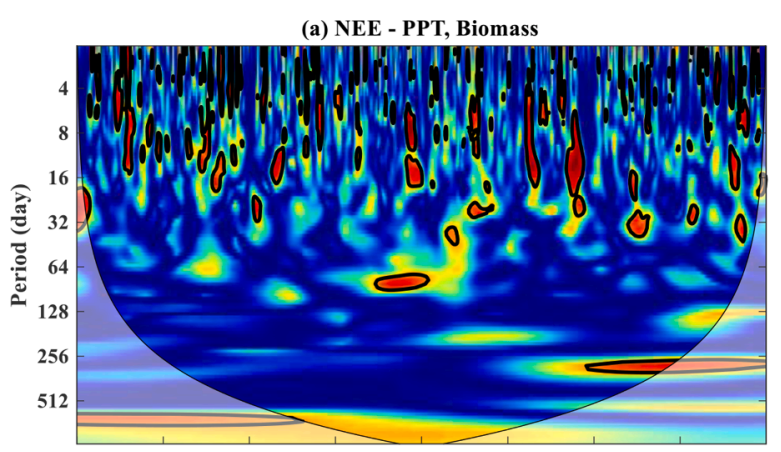

(c) NEE - Biomass, PAR

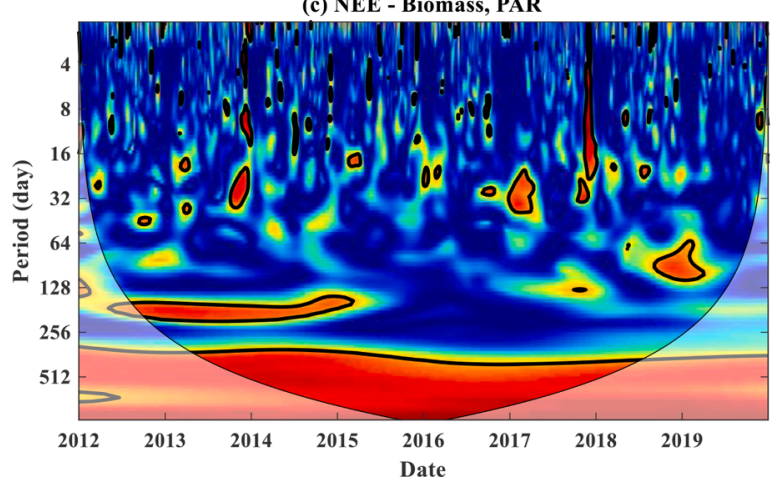

(b) NEE - Biomass, PPT

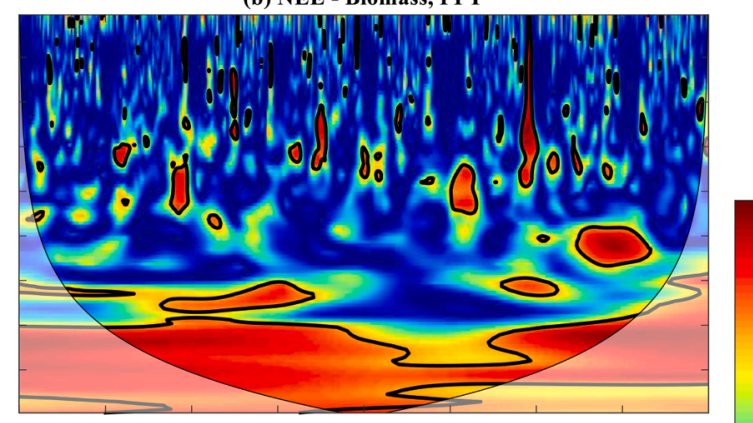

(d) NEE - Biomass, Tair

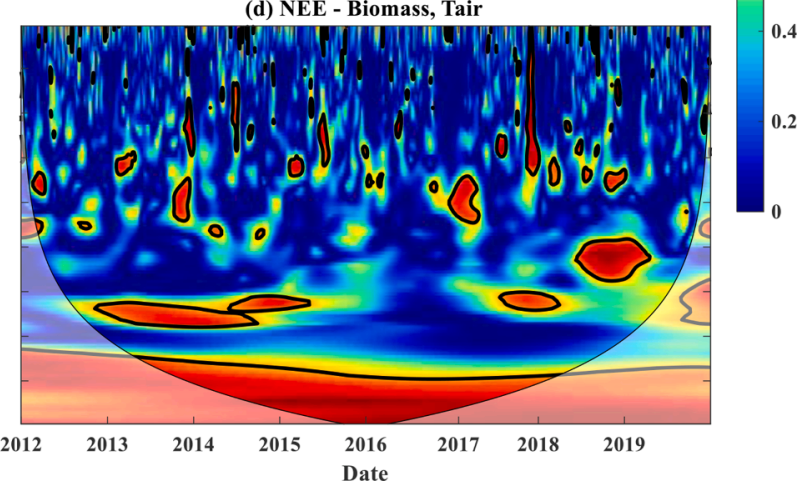

Figure 5. Partial wavelet coherence (PWC) (a) between net ecosystem $\mathrm{CO}_{2}$ exchange (NEE) and precipitation (PPT) after removing the effects of sum of aboveground and underground biomass, (b) between NEE and biomass after removing the effects of PPT, (c) between NEE and biomass after removing the effects of photosynthetic active radiation (PAR), (d) between NEE and biomass after removing the effects of air temperature ( $T_{\text {air }}$ ) from 2012 to 2019. Black contour lines represent the 0.05 significance level, and the thin line indicates the cone-of-influence that delimits the region not influenced by edge effects.
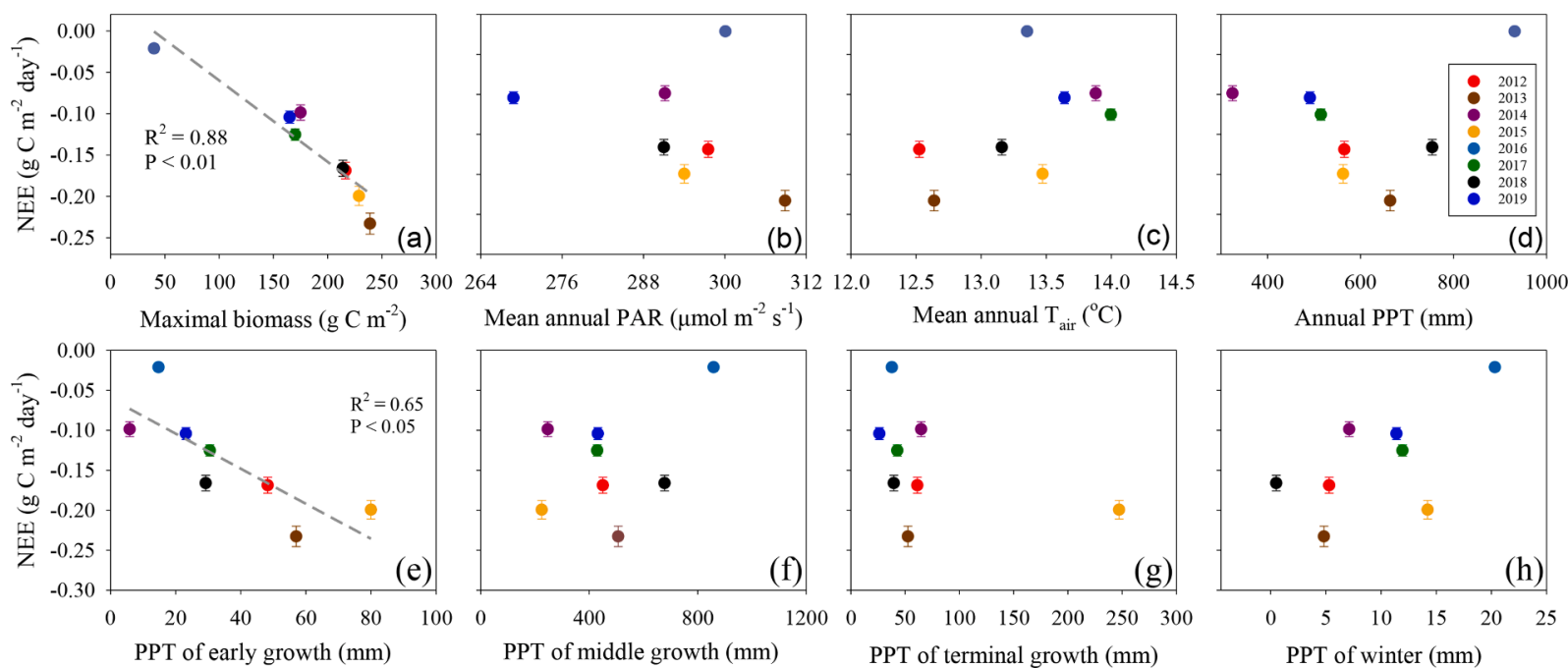

Mean annual $\mathrm{T}_{\text {air }}\left({ }^{\circ} \mathrm{C}\right)$
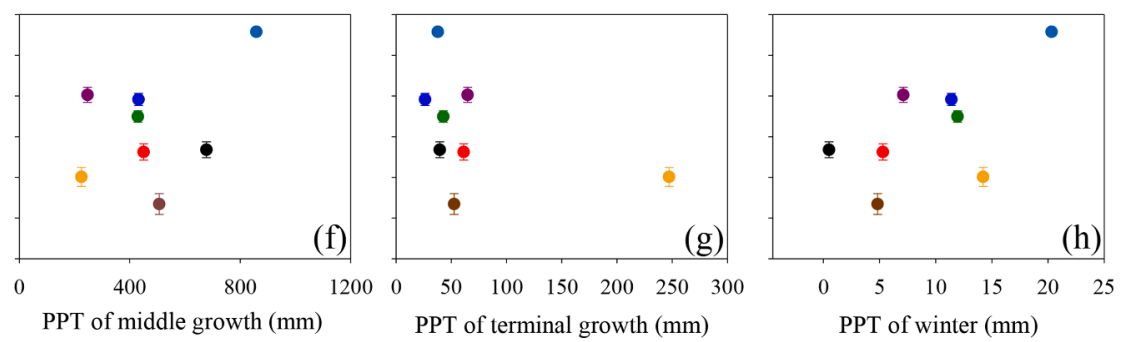

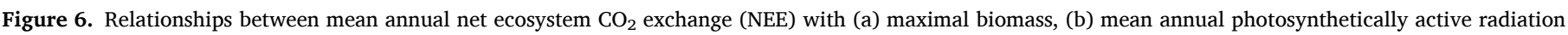

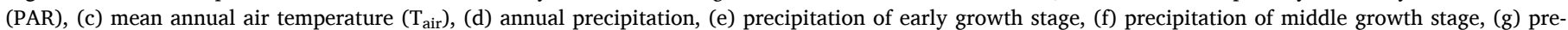
cipitation of terminal growth stage, and (h) precipitation of winter from 2012 to 2019. Bars represent means \pm SE, each dot represents 1 year.

\section{Discussion}

\subsection{Influence mechanism of seasonal precipitation distribution on annual} NEE

Our results demonstrated that annual NEE was more sensitive to seasonal precipitation, especially during the early growth stage. Firstly, as the sensitive and tolerant of vegetation during different growth stages are different, and studies have found that the salt-tolerant ability was relatively low at the young seedling stage, and seed germination of
S. salsa decreased significantly with increased salinity (Duan et al., 2007). Secondly, low precipitation accompanied by high irradiance and air temperature is increasing during the early growth stage, which would promote seed germination and plant growth, but at the same time, led to a build-up of soil salinity (Han et al., 2018). The inhibition effect due to salinity stress was stronger than the promotion effect, especially when soil was dry (Chu et al., 2018). Thus, decreased germination rate caused by high salinity inhibited canopy development, resulting in reduced ecosystem photosynthesis and productivity (Heinsch et al., 2004). 

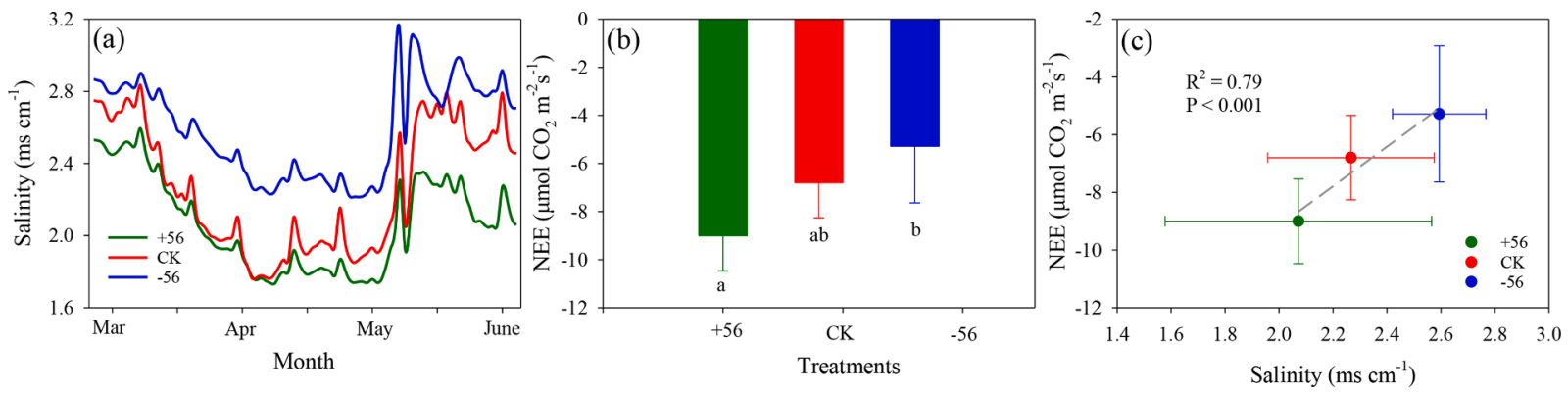

Figure 7. Precipitaiton (a), soil salinity at $10 \mathrm{~cm}$ depth (a) and net ecosystem $\mathrm{CO}_{2}$ exchange (NEE) (b) measured in spring precipitation distribution experiment on a salt marsh in spring 2020 . Bars represent means \pm SE. +56 : spring precipitation increased by $56 \%$ compared to CK; CK: mean spring precipitation from 1988 to 2018 ; -56 : spring precipitation decreased by $56 \%$ compared to CK.

Seasonal not annual precipitation drives inter-annual NEE variability in the salt marsh. On the one hand, if annual precipitation is high but the precipitation during the early growth stage is low, especially during an extended dry early growth stage, water-soluble salts from groundwater are transported upward to the root zone and soil surface through capillary rise (Fig. 8). Exposed to increasing salinity levels, the formation of new leaf buds would be inhibited (Forbrich et al., 2018). With more frequent occurrences of continuous limited precipitation, drought may jeopardize the $S$. salsa, much as they have hurt "blue carbon" of coastal wetland at a broader scale. The reduced precipitation combined with increased soil salinity lowers stomatal conductance thus reducing vegetation water use, leading to suppressed vegetation germination and biomass accumulation (Hanson et al., 2016). Besides, high annual precipitation would increase precipitation during the middle growth stage, which would cause episodic flooding (Wei et al., 2020a). The waterlogged stress caused by precipitation would inhibit net photosynthetic rate and net $\mathrm{CO}_{2}$ uptake (Han et al., 2015). On the other hand, as vegetation growth is primarily limited by salinity (Tian et al., 2020), if annual precipitation is low but the precipitation during the early growth stage is high, the inflow of available water after precipitation during the early growth stage tends to decrease the salinity, which may promote vegetation germination and canopy development, and consequently promote biomass accumulation and net $\mathrm{CO}_{2}$ absorption (Heinsch et al., 2004, Forbrich et al., 2018). The daily aggregated NEE-GPP displayed consistent linear correlation during different growth stages across the 8 years (Fig. S1a), indicating that NEE and GPP showed similar distributions of importance. Noting that the years with strong annual carbon sink (e.g. 2012, 2013, 2015 and 2018) corresponds to early growth stages with more data fell above the 1:1 line, indicating the more net $\mathrm{CO}_{2}$ accumulation and stronger $\mathrm{CO}_{2}$ sink strength (Fig. S1b). Biomass was correlated with GPP (Fig. S3), and GPP declined when freshwater availability was low and salinity was high (Heinsch et al., 2004, Li et al., 2017). Corresponding to high precipitation events during the early growth stage, biomass values were higher during summer months in years with more precipitation $(2012,2013,2015,2017,2018)$ than the other years (Fig. 2), indicating stronger C sink during these years (Fig. 3). In concert with our previous findings in a field experiment soil salinity decreased with added precipitation and promoted vegetation growth during the early growing season (Chu et al., 2019). These observations support the finding that timing of precipitation is more important for plant growth than its magnitude in salt marshes (Ru et al., 2017).

Previous studies have also shown that seasonal not annual precipitation drives annual $\mathrm{CO}_{2}$ assimilation and sequestration potential of ecosystems through changing vegetation biomass accumulation, or through soil compaction and mineralization (O'Connor et al., 2010, Zeppel et al., 2014). For example, researches in arid and semiarid regions have found that seasonal precipitation determines not only

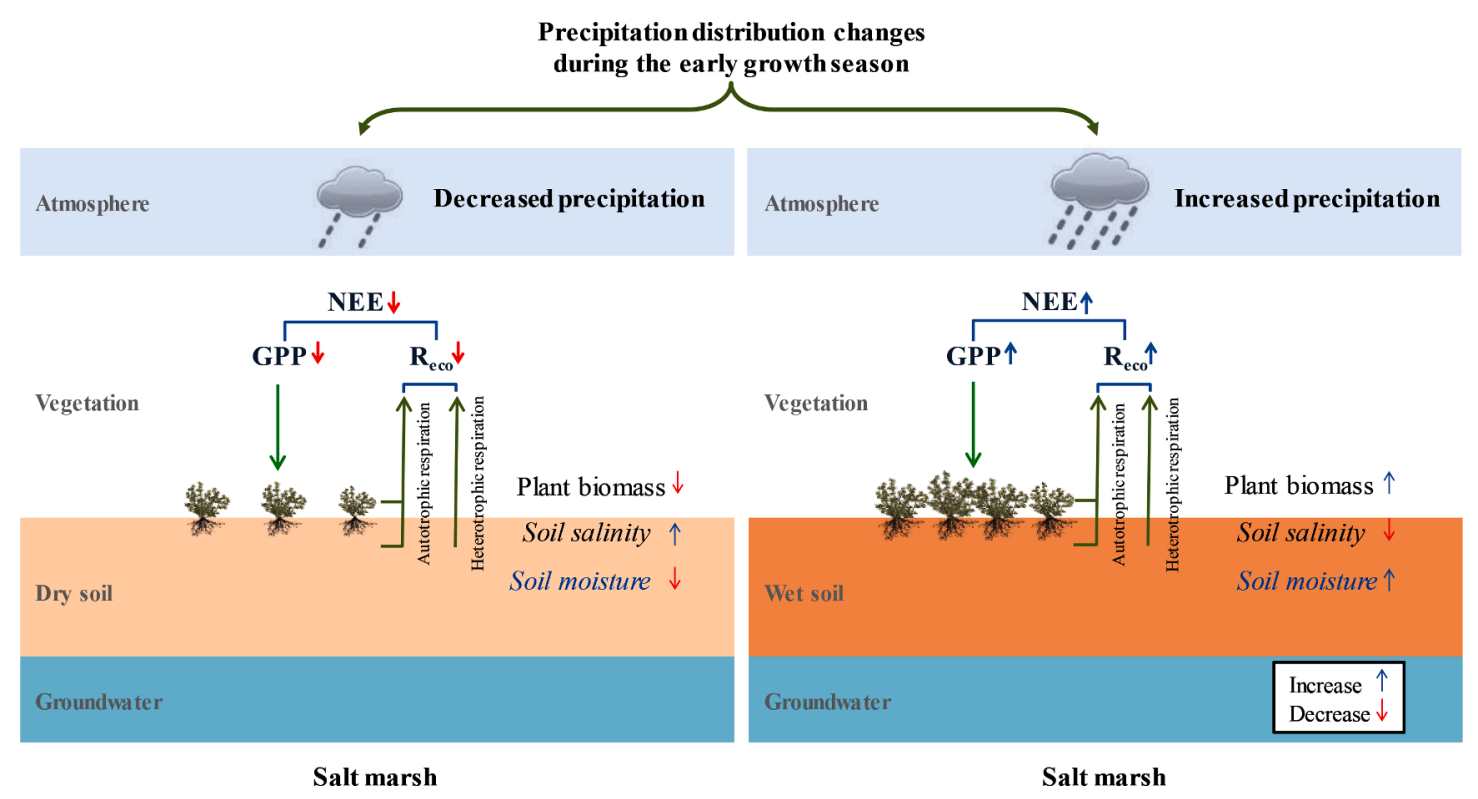

Figure 8. A schematic diagram illustrating the effect of precipitation distribution during the early growth season on ecosystem $\mathrm{CO}_{2}$ exchange in coastal wetland. Variation of precipitation during the early growth would affect vegetation germination, growth and biomass accumulation by impacting on soil moisture and soil salinity, which ultimately influence NEE via regulating GPP and R eco. . 
vegetation growth and biomass accumulation response to carbon dioxide (Coe et al., 2012, Hovenden et al., 2014), but also C release through soil respiratory processes (Ru et al., 2017). Some findings are contradictory to our results that the interannual variation of NEE, soil and microbial respiration resulted from the difference in mean annual precipitation (Gherardi et al., 2018, Lyu et al., 2018). The contrasting findings in different studies might have resulted from the difference of soil texture, species composition and environmental conditions (Prevey et al., 2014, Osland et al., 2018). As a result, responses to precipitation over time are likely to differ among the study sites.

\subsection{Implications for salt marshes carbon budget under changes in soil water-salt environment}

In this paper, our 8-year field measurements demonstrated that increased early growth stage precipitation promoted biomass accumulation and had a promoting effect on annual carbon sink capacity. The result revealed that seasonal precipitation had significant influence on carbon exchange in this salt marsh. The result is consistent with the conclusion of previous studies that seasonal precipitation plays important roles in regulating annual C budget (Beier et al., 2012; Li et al., 2020b). Specially under the background of warm and dry environment (Han et al., 2018), higher temperature and decreased precipitation during the early growth will enhance soil moisture evaporation and increase soil salinity, which will influence biomass accumulation and annual C budget. The strong dependence of annual NEE upon precipitation amount during the early growth stage, but not upon those in the annual, middle or terminal growth stages, could largely be attributed to the immediate and legacy effects on soil water-salt environment and concomitant changes in vegetation germination rate, which determine the vegetation growth and net carbon absorption ability in the entire growing season. We have a fairly good understanding of atmospheric carbon sink to seasonal precipitation but few studies incorporate belowground responses in terms of soil C biogeochemical cycling. Unlike in terrestrial systems, NEE in tidal wetlands may not fully represent net $\mathrm{C}$ accumulation, as considerable amounts of organic and inorganic forms of C are exchanged laterally with tidal and estuarine waters (Cai, 2011, Wang et al., 2017, Forbrich et al., 2018), but few studies investigate $C$ in sediments responses in terms of long-term burial rates, resulting in the underestimate the capacity of carbon sink capacity. Hence, accurately quantifying the difference between NEE measurements and burial rates is essential to estimate the mass loss of $C$ that is not exchanged with the atmosphere (Forbrich et al., 2018).

Climate warming is projected to perturb the global water cycle in future (Milly et al., 2005; Meraner et al., 2013). Precipitation patterns including the timing, magnitude, and seasonality of precipitation are predicted to undergo substantial alterations in the future (Zeppel et al., 2014, Emery et al., 2019), and salt marshes organisms may be more responsive to such changes than to shifts in only mean annual precipitation. The drying and wetting cycles induced by seasonal precipitation can not only effect soil water-salt environment but also soil aerobic and anaerobic environment, which would finally have a profound impact on the carbon biogeochemical cycle and carbon balance (Goldstein et al., 2014; Li et al., 2020a). Besides, in the context of sea level rise, tidal variation induced by sea level rise is a neglected tidal hydrology, which would significantly influence salt marsh processes. Soil alternate drying-wetting is an important determinant of soil redox condition, which will further influence microbial activity and decomposition rates of soil organic matter (Chivers et al., 2009). Traditional model concepts of ecosystem $\mathrm{C}$ are developed primarily from knowledge gained in mesic ecosystem, thus they fail to capture seasonal precipitation dynamics (Carbone et al., 2011). Considering that precipitation regimes are expected to become increasingly variable in future, precipitation-induced hydrological environment variability accompanied by water-salt transport might aggravate the destabilization capacity in the salt marshes, which may be one of the key sources of the uncertainty in the modeled ecosystem C cycle.

\section{Declaration Of Competing Interest}

The authors declare that they have no known competing financial interests or personal relationships that could have appeared to influence the work reported in this paper.

\section{Acknowledgements}

This work was founded by the Strategic Priority Research Program of the Chinese Academy of Sciences, China (XDA23050202), the National Nature Science Foundation of China (41671089, 42071126, 41706097), International Science Partnership Program of the Chinese Academy of Sciences (121311KYSB20190029), Natural Science Foundation of Shandong Province (ZR2019BC106), NSFC-Shandong Union Project (U1906220) and Open Research Fund Program of Shandong Provincial Key Laboratory of Eco-Environmental Science for Yellow River Delta (Binzhou University) (2020KFJJ02). We are grateful for the support from Yellow River Delta Ecological Research Station of Coastal Wetland, CAS, and also thank anonymous reviewers for their expert advice and comments.

\section{Supplementary materials}

Supplementary material associated with this article can be found, in the online version, at doi:10.1016/j.agrformet.2021.108557.

\section{Reference}

Abdul-Aziz, O.I., Ishtiaq, K.S., Tang, J.W., Moseman-valtierra, S., Kroeger, K.D. Gonneea, M.E., Mora, J., Morkesdki, K., 2018. Environmental controls, emergent scaling, and predictions of greenhouse gas (GHG) fluxes in coastal salt marshes. J. Geophys. Res.-Biogeosci. 123, 2234-2256.

Beier, C., Beierkuhnlein, C., Wohlgemuth, T., Penuelas, J., Emmett, B., Körner, C., de Boeck, H.J., Christensen, J.H., Leuzinger, S., Janssens, I.A., Hansen, K., 2012. Precipitation manipulation experiments-challenges and recommendations for the future. Ecol. Lett. 15, 899-911.

Cai, W.J., 2011. Estuarine and coastal ocean carbon paradox: $\mathrm{CO}_{2}$ sinks or sites of terrestrial carbon incineration? Annu. Rev. Mar. Sci. 3, 123-145.

Carbone, M.S., Still, C.J., Ambrose, A.R., Dawson, T.E., Williams, A.P., Boot, C.M., Schaeffer, S.M., Schimel, J.P., 2011. Seasonal and episodic moisture controls on plant and microbial contributions to soil respiration. Oecologia 167, 265-278.

Chivers, M.R., M.R.Turetsky, J.M.Waddington, Harden, J.W., McGuire, A.D., 2009. Effects of experimental water table and temperature manipulations on ecosystem $\mathrm{CO}_{2}$ fluxes in an Alaskan rich fen. Ecosystems 12, 1329-1342.

Chmura, G.L., Kellman, L., Guntenspergen, G.R., 2011. The greenhouse gas flux and potential global warming feedbacks of a northern macrotidal and microtidal salt marsh. Environ. Res. Lett. 6, 044016.

Chu, X.J., Han, G.X., Xing, Q.H., Xia, J.Y., Sun, B.Y., Li, X.G., Yu, J.B., Li, D.J., Song, W. M., 2019. Changes in plant biomass induced by soil moisture variability drive interannual variation in the net ecosystem $\mathrm{CO}_{2}$ exchange over a reclaimed coastal wetland. Agric. For. Meteorol. 264, 138-148.

Chu, X.J., Han, G.X., Xing, Q.H., Xia, J.Y., Sun, B.Y., Yu, J.B., Li, D.J., 2018. Dual effect of precipitation redistribution on net ecosystem $\mathrm{CO}_{2}$ exchange of a coastal wetland in the Yellow River Delta. Agric. For. Meteorol. 249, 286-296.

Coe, K.K., Belnap, J., Sparks, J.P., 2012. Precipitation-driven carbon balance controls survivorship of desert biocrust mosses. Ecology 93, 1626-1636.

Drake, K., Halifax, H., Adamowicz, S.C., Craft, C., 2015. Carbon Sequestration in Tidal Salt Marshes of the Northeast United States. Environ. Manage. 56, 998-1008.

Duan, D.Y., Li, W.Q., Liu, X.J., Ouyang, H., An, P., Duan, D.Y., Liu, W.Q., 2007. Seed germination and seedling growth of Suaeda salsa under salt stress. Ann. Bot. Fenn. $44,161-169$.

Emery, H.E., Angell, J.H., Fulweiler, R.W., 2019. Salt marsh greenhouse gas fluxes and microbial communities are not sensitive to the first year of precipitation change. J. Geophys. Res.-Biogeosci. 124, 1071-1087.

Forbrich, I., Giblin, A.E., Hopkinson, C.S., 2018. Constraining marsh carbon budgets using long-term $\mathrm{C}$ burial and contemporary atmospheric $\mathrm{CO}_{2}$ fluxes. J. Geophys. Res.-Biogeosci. 123, 867-878.

Gherardi, L.A., Sala, O.E., 2018. Effect of interannual precipitation variability on dryland productivity: a global synthesis. Glob. Change Biol. 25, 269-276.

Goldstein, L.J., Suding, K.N., 2014. Intra-annual rainfall regime shifts competitive interactions between coastal sage scrub and invasive grasses. Ecology 95, 425-435.

Han, G., Chu, X., Xing, Q., Li, D., Yu, J., Luo, Y., Wang, G., Mao, P., Rafique, R., 2015. Effects of episodic flooding on the net ecosystem $\mathrm{CO}_{2}$ exchange of a supratidal wetland in the Yellow River Delta. J. Geophys. Res.-Biogeosci. 120, 1506-1520. 
Han, G., Luo, Y., Li, D., Xia, J., Xing, Q., Yu, J., 2014. Ecosystem photosynthesis regulates soil respiration on a diurnal scale with a short-term time lag in a coastal wetland. Soil Biol. Biochem. 68, 85-94.

Han, G., Sun, B., Chu, X., Xing, Q., Song, W., Xia, J., 2018. Precipitation events reduce soil respiration in a coastal wetland based on four-year continuous field measurements. Agric. For. Meteorol. 256, 292-303.

Hanson, A., Johnson, R., Wigand, C., Oczkowski, A., Davey, E., Markham, E., 2016. Responses of spartina alterniflora to multiple stressors: changing precipitation patterns, accelerated sea level rise, and nutrient enrichment. Estuaries Coasts 39, $1376-1385$.

He, G., Wang, K., Zhong, Q., Zhang, G., Bosch, C., Wang, J., 2021. Agroforestry reclamations decreased the $\mathrm{CO}_{2}$ budget of a coastal wetland in the Yangtze estuary. Agricultural and Forest Meteorology 296, 108212.

Heinsch, F.A., Heilman, J.L., McInnes, K.J., Cobos, D.R., Zuberer, D.A., Roelke, D.L., 2004. Carbon dioxide exchange in a high marsh on the Texas Gulf Coast: effects of freshwater availability. Agric. For. Meteorol. 125, 159-172.

Hoover, D.J., Odigie, K.O., Swarzenski, P.W., Barnard, P., 2017. Sea-level rise and coasta groundwater inundation and shoaling at select sites in California. USA. J. Hydrol.Reg. Stud. 11, 234-249.

Hovenden, M.J., Newton, P.C.D., Wills, K.E., 2014. Seasonal not annual rainfall determines grassland biomass response to carbon dioxide. Nature 511, 583-586.

Hu, M., Ren, H., Ren, P., Li, J., Wilson, B.J., Tong, C., 2017. Response of gaseous carbon emissions to low-level salinity increase in tidal marsh ecosystem of the min river estuary, southeastern china. J. Environ. Sci. 52, 210-222.

Jia, X., Zha, T.S., Gong, J.N., Zhang, Y.Q., Wu, B., Qin, S.G., Peltola, H.L., 2018. Multiscale dynamics and environmental controls on net ecosystem $\mathrm{CO}_{2}$ exchange over a temperate semiarid shrubland. Agric. For. Meteorol. 259, 250-259.

Li, M., Zhang, X.Z., Niu, B., He, Y.T., Wang, X.T., Wu, J.S., 2020a. Changes in plant species richness distribution in Tibetan alpine grasslands under different precipitation scenatios. Glob. Ecol. Conserv. 21, e00848.

Li, P., Sayer, E.J., Jia, Z., Liu, W., Wu, Y., Yang, Sen, Wang, C., Yang, L., Chen, D., Bai, Y., Liu, L., 2020b. Deepened winter snow cover enhances net ecosystem exchange and stabilizes plant community composition and productivity in a temperate grassland. Glob. Change Biol. 26, 3015-3027.

Liu, L., Wang, X., Lajeunesse, M.J., Miao, G., Piao, S., Wan, S., Wu, Y., Wang, Z., Yang, S., Li, P., 2016. A cross-biome synthesis of soil respiration and its determinants under simulated precipitation changes. Glob. Change Biol. 22, 1394-1405.

Lyu, M., Litton, C.M., Giardina, C.P., 2018. Inter-annual variation in precipitation alters warming-induced belowground carbon fluxes in tropical montane wet forests. AGU Fall Meeting Abstracts.

Morris, J.T., Sundareshwar, P., Nietch, C.T., Kjerfve, B., Cahoon, D., 2002. Responses of coastal wetlands to rising sea level. Ecology 83, 2869-2877.

Ng, E.K.W., Chan, J.C.L., 2012. Geophysical applications of partial wavelet coherence and multiple wavelet coherence. J. Atmos. Ocean. Technol. 29, 1845-1853.

O'Connor, T.G., Haines, L.M., Snyman, H.A., 2010. Influence of precipitation and species composition on phytomass of a semi-arid african grassland. J. Ecol. 89, 850-860.

Osland, M.J., Gabler, C.A., Grace, J.B., Day, R.H., McCoy, M.L., McLeod, J.L., From, A.S., Enwright, N.M., Feher, L.C., Stagg, C.L., Hartley, S.B., 2018. Climate and plant controls on soil organic matter in coastal wetlands. Glob. Change Biol. 24, $5361-5379$.

Poffenbarger, H.J., Needelman, B.A., Megonigal., J.P., 2011. Salinity influence on methane emissions from tidal marshes. Wetlands $31,831-842$.
Polsenaere, P., Lamaud, E., Lafon, V., Bonnefond, J.M., Bretel, P., Delille, B., Deborde, J., Loustau, D., Abril, G., 2012. Spatial and temporal $\mathrm{CO}_{2}$ exchanges measured by Eddy Covariance over a temperate intertidal flat and their relationships to net ecosystem production. Biogeosciences 9, 249-268.

Prevey, Janet S., Seastedt, T.R., Wilson, S., 2014. Seasonality of precipitation interacts with exotic species to alter composition and phenology of a semi-arid grassland. J. Ecol. 102, 1549-1561.

Ru, J., Zhou, Y., Hui, D., Zheng, M., Wan, S., 2017. Shifts of growing-season precipitation peaks decrease soil respiration in a semiarid grassland. Glob. Change Biol. 24, 1001-1011.

Schedlbauer, J.L., Oberbauer, S.F., Starr, G., Jimenez, K.L., 2010. Seasonal differences in the $\mathrm{CO}_{2}$ exchange of a short-hydroperiod Florida Everglades marsh. Agric. For. Meteorol. 150, 994-1006.

Sun, B., Yan, L., Jiang, M., Li, X., Han, G., Xia, J., 2021. Reduced magnitude and shifted seasonality of $\mathrm{CO}_{2}$ sink by experimental warming in a coastal wetland. Ecology 102 (2), e03236.

Suyker, A.E., Verma, S.B., 2012. Gross primary production and ecosystem respiration of irrigated and rainfed maize-soybean cropping systems over 8 years. Agric. For. Meteorol. 165, 12-24.

Tian, F., Hou, M., Qiu, Y., Zhang, T., Yuan, Y., 2020. Salinity stress effects on transpiration and plant growth under different salinity soil levels based on thermal infrared remote (TIR) technique. Geoderma 357, 113961.

Wang, S.R., Di Iorio, D., Cai, W.J., Hopkinson, C.S., 2017. Inorganic carbon and oxygen dynamics in a marsh-dominated estuary. Limnol. Oceanogr. 63, 47-71.

Webb, E.K., Pearman, G.I., Leuning, R., 1980. Correction of flux measurements for density effects due to heat and water vapor transport. Q. J. R. Meteorol. Soc. 106, 85-100.

Wei, S., Han, G., Jia, X., Song, W., Wu, H., 2020a. Tidal effects on ecosystem $\mathrm{CO}_{2}$ exchange at multiple timescales in a salt marsh in the Yellow River Delta. Estuar. Coast. Shelf Sci. 238, 106727.

Wei, S., Han, G., Chu, X., Song, W., Wu, H., 2020b. Effect of tidal flooding on ecosystem $\mathrm{CO}_{2}$ and $\mathrm{CH}_{4}$ fluxes in a salt marsh in the Yellow River Delta. Estuar. Coast. Shelf Sci. $232,106512$.

Wieski, K., Pennings, S.C., 2014. Climate drivers of Spartina alterniflora saltmarsh production in Georgia. USA. Ecosystems 17, 473-484.

Wu, H., Lu, X., Wu, D., Song, L., Yan, X., Liu, J., 2013. Ant mounds alter spatial and temporal patterns of $\mathrm{CO}_{2}, \mathrm{CH}_{4}$ and $\mathrm{N}_{2} \mathrm{O}$ emissions from a marsh soil. Soil Biol. Biochem. 57, 884-891.

Yando, E.S., Osland, M.J., Willis, J.M., Day, R.H., Krauss, K.W., Hester, M.W., 2016. Salt marsh-mangrove ecotones: using structural gradients to investigate the effects of woody plant encroachment on plant-soil interactions and ecosystem carbon pools. J. Ecol. 104, 1020-1031.

Yao, R., Yang, J., 2010. Quantitative evaluation of soil salinity and its spatial distribution using electromagnetic induction method. Agricultural Water Management 97, 1961-1970.

Zeppel, M.J.B., Wilks, J.V., Lewis, J.D., 2014. Impacts of extreme precipitation and seasonal changes in precipitation on plants. Biogeosciences 11, 3083-3093.

Zhong, Q., Wang, K., Lai, Q., Zhang, C., Zheng, L., Wang, J., 2016. Carbon dioxide fluxes and their environmental control in a reclaimed coastal wetland in the Yangtze Estuary. Estuaries Coasts 39, 344-362. 